\title{
WING-LENGTH IN SOME NEW ENGLAND ACRIDIDAE.-I.
}

\section{BY ALBERT P. MORSE, WFLLESLEY, MASS.}

The title in full of this paper may be stated as "Length of wings as an evidence of specific distinctness and its value as a diagnostic character in reference to some New England Acrididae." In using the term length of wing the length of the wing-covers or tegmina is in many instances included.

It was formerly the custom among writers on this family to base specific distinctness more or less largely on a difference in the length of wing presented by some closely allied forms, and to give keys for the determination of species in which this was used as a diagnostic character.*

My experience with New England forms has led me to conclude that this character of wing-length as found in some of these is extremely unreliable, and that the description of a new species founded wholly or largely on this character should be received with great caution.

As an instance of specific variability on this point let me cite the case of Opomala brachyptera Scudd. This locust, a well-known and widely-distributed species, possesses ordinarily

*A still more unsatisfactory practice was that of com. paring the wing.length to the abdomen, thus: "Tip of wings passing abdomen." The abdomen of the female locust is so variable in length, owing to size and number of eggs, and extension due to oviposition, that it seems strange that any one should have used this rela. tion when one of equal practical value not subject to variation exists, viz: comparison with the hind femora. wing-covers extending on the hind femora in the male to about one-half the distance to the tip, in the female to about one-fourth or one-third the distance to the tip, the wings in both sexes being nearly or quite aborted. In July, I 892, I had the good fortune to capture a female similar in all respects to the ordinary form but having the tegmina extending to the end of the femora and the wings fully developed. Could it be another species? Further search soon resulted in the capture of a normal male brachyptera and left little doubt in my mind that here was a case of reversion to the earlier long-winged form of female. Search in another locality several miles distant resulted in the capture of over fifty specimens among which were four long-winged females and two long-winged males. I have since obtained another longwinged male from a neighboring town and Mr. Scudder has one in his collection from Iowa.

Turning to the genus Chloealtis, or as it is also known, Chrysochraon, we find three forms described as occurring in New England. In one of these, C. conspersa, the female possesses abortive wings and the tegmina rarely reach half-way to end of femora. Both wings and tegmina are somewhat more developed in the male but not enough to serve as organs of flight. I 
have never seen any long-winged specimens in New England but Mr. W. S. Blatchley states (Can. ent., I891, 76) that he has taken a female in Indiana.

C. conspersa is quite uniform in coloring, being invariably brown or strawcolor, never green, while the other two forms or so-called species present an interesting case of dimorphism in color, specimens of both sexes being partly or wholly either brown or green; most commonly, the females are wholly green or brown and the males green above with brown sides, and mating with females of either color.

Ordinarily the wings and tegmina are of about equal length, reaching, in the male, about half-way down the femora, and in the female rather less, in the form called $C$. viridis, and in the other form, C. punctulata, reaching to the end of femora. Specimens occur having wings and tegmina of an intermediate length, and short-winged males mate freely with long-winged females of either color; long-winged males appear to be extremely scarce, but all the other forms are common, the long-winged much less so than the short-winged.

No other characters of more than individual importance are presented by these two forms to indicate them as distinct. The two are found associated in time and place, and mated, whence I conclude that without a doubt the longwinged, less common form, is the ancestral form which is giving place to the other.

Continuing in another genus of the Tryxalinae,-Stenobothrus, - we meet two forms, quite variably colored and presenting a marked contrast in length of tegmina and wings, which have long been considered to belong to one species, S. curtipennis and S. longipennis. These are about equally plentiful. The long-winged form frequently makes use of its wings in locomotion while the other is obliged to resort to a more prosaic mode of progression.

Take next the two species $S$. aequalis and $S$. maculipennis. Here structural differences in the vertex and pronotum are usually, but not always, accompanied by a difference in length of wing serving to distinguish the two species. Owing to the fact that long-winged individuals occur in the short-winged species and to the wide variation in color presented by both species they have been much confused and misunderstood by various authors.

\section{PROCEEDINGS OF THE CLUB.}

9 June, 1893 . The I79th meeting was held at 156 Brattle St., Mr. S. H. Scudder in the chair.

Mr. H. G. Dyar exhibited specimens of Kodiosoma eavesii collected by Mr. L. B.
Lembert of Yosemite, Cal., and remarked upon the scarcity of the species of Kodiosoma in collections.

Mr. A. P. Morse read a paper on Winglength in some New England Acrididae and exhibited specimens in illustration.

Mr. S. H. Scudder exhibited a folding net sent to the club from Switzerland. 

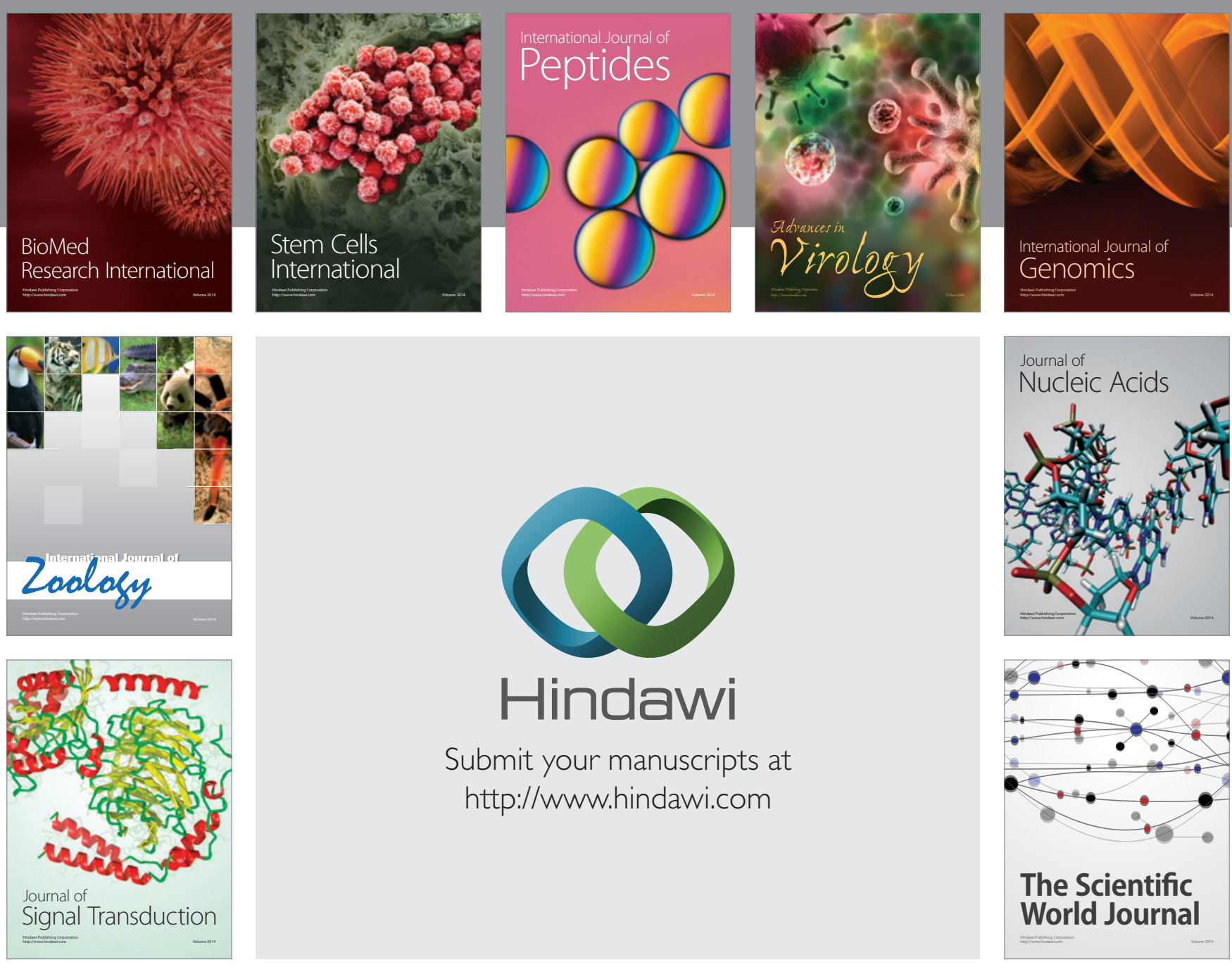

Submit your manuscripts at

http://www.hindawi.com
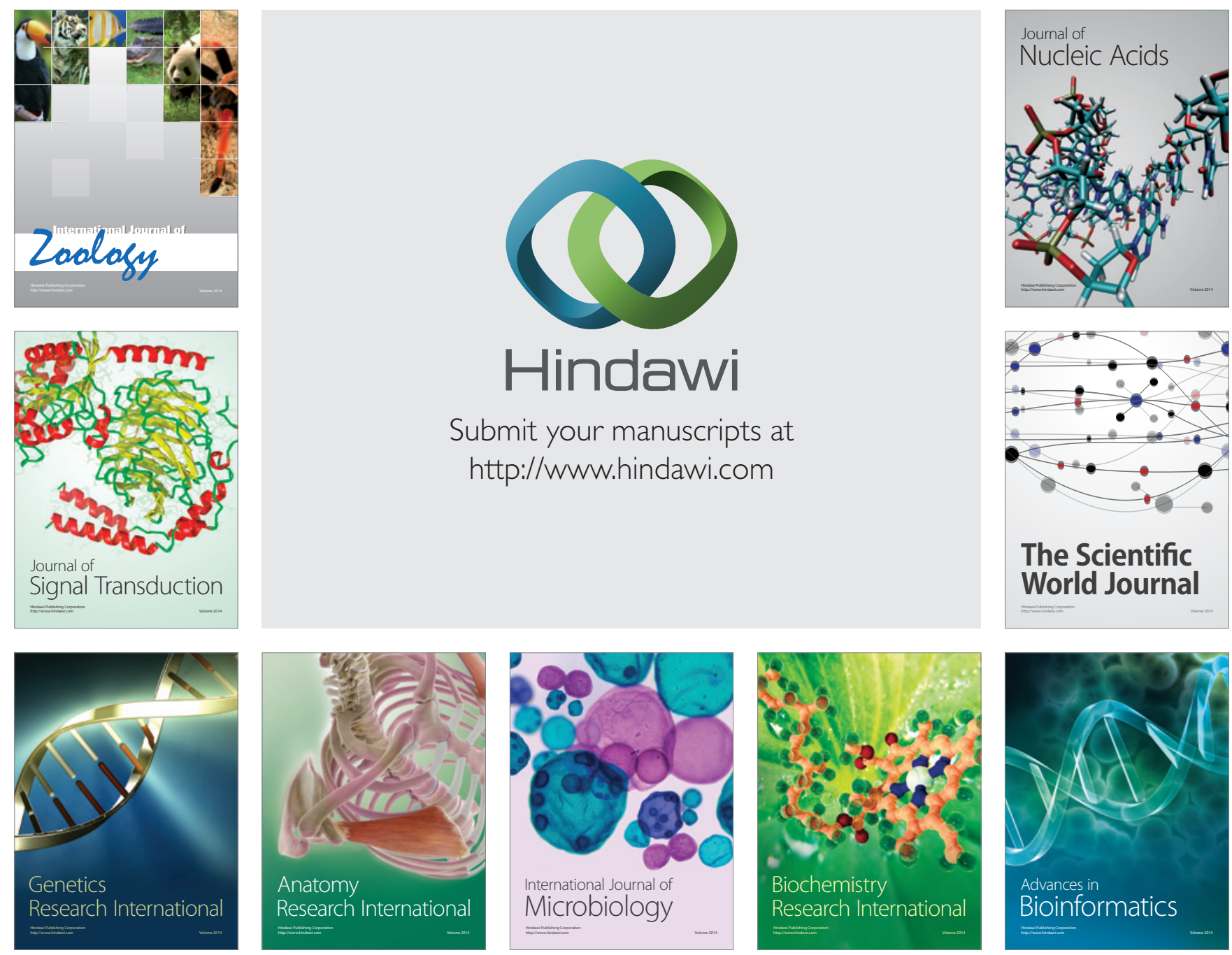

The Scientific World Journal
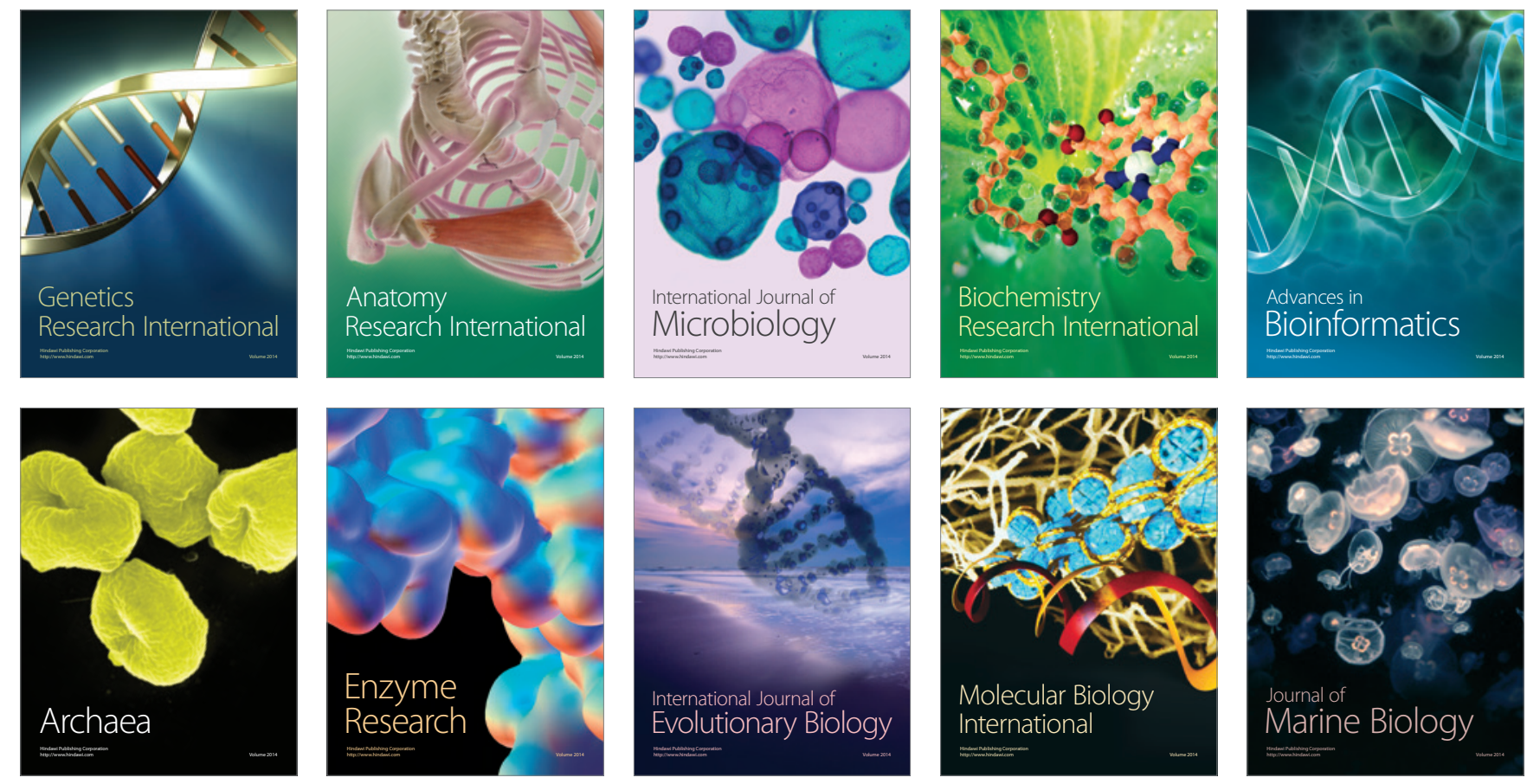